\title{
INFLUÊNCIA DA MICROESTRUTURA NA APLICAÇÃO DE AÇOS MULTICONSTITUÍDOS DA CLASSE 980 MPA
}

Paulo José Duarte Rodrigues ' Fernando de Souza Costa Dagoberto Brandão Santos ${ }^{3}$

\section{Resumo}

No atual cenário de modernização automotiva, eficiência energética, redução de emissões e ganho em segurança são essenciais. Tais aspectos impulsionam o aprimoramento dos Aços Avançados de Alta Resistência, tornando-os cada vez mais aptos para o uso em diferentes partes da estrutura do veículo. A etapa de seleção desses materiais é primordial, tendo em vista o incremento do índice de falhas quando se comparam esses aços aos convencionais. A microestrutura é um dos principais fatores a considerar, pois para uma mesma classe de resistência, podem existir resultados divergentes na estampagem das peças, em função da geometria e dos esforços de conformação implícitos. O presente trabalho aborda o desenvolvimento de diferentes concepções de aços multifásicos da classe $980 \mathrm{MPa}$, voltadas para aplicação em peças com estiramento de flange, objetivando melhores resultados de expansão de furo. Os novos projetos apresentaram diferenças microestruturais e nas propriedades em tração, correlacionadas aos melhores resultados de expansão de furo.

Palavras-chave: Aço multifásico; Expansão de furo; Estiramento de flange.

\section{INFLUENCE OF MICROSTRUCTURE IN THE APPLICATION OF 980 MPA CLASS MULTICONSTITUENT STEELS}

\begin{abstract}
In the current scene of automotive modernization, energy efficiency, emissions reduction and gains in vehicle safety are essential. These aspects drive the improvement of Advanced High Strength Steels, making them increasingly suitable for different structural parts of the vehicle. The selection stage of these materials is significant, in view of the increase in the failure rate when comparing these with conventional steels. The microstructure is one of the main factors to consider, because for the same strength class, there may be divergent results in the drawing of the parts depending on their geometry and the implicit forming requirements. The present work deals with the development of different designs of Multiphase steel $980 \mathrm{MPa}$ class, aimed at application in pieces with stretch flangeability, aiming better hole expansion results. The new design presented microstructural and tensile proprieties differences which are correlated to the best results of hole expansion ratio.
\end{abstract}

Keywords: Multiphase steel; Hole expansion; Stretch flangeability.

\section{INTRODUÇÃO}

A consolidação do uso de aços de ultra-alta resistência caminha junto aos avanços tecnológicos do setor automotivo. Além da produção de materiais mais resistentes, existe a necessidade de aprimorá-los para aplicação em peças de geometria mais complexa, que exigem maiores esforços de conformação relacionados ao estiramento de flanges. A microestrutura do aço é o principal fator para obter sucesso [I]. O aço Dual Phase, de microestrutura tipicamente formada por ferrita $(F)$ e martensita $(M)$, combina resistência e ductilidade, sendo adequado para peças onde predomina o estiramento puro. Entretanto, quando prevalece a ductilidade local, como é caso de operações por flangeamento de bordas, a microestrutura deve ser mais homogênea, refinada e com menor diferença de dureza entre os constituintes [ $I$ ], a fim de prevenir a iniciação de trincas, geralmente nucleadas na interface entre esses constituintes [2].

'Controle Integrado da Qualidade, Usiminas, Ipatinga, MG, Brasil. E-mail: paulo.jose@usiminas.com

${ }^{2}$ Centro de Pesquisa, Usiminas, Ipatinga, MG, Brasil.

${ }^{3}$ Departamento de Engenharia Metalúrgica e de Materiais, Universidade Federal de Minas Gerais - UFMG, Belo Horizonte, MG, Brasil.

2176-1523 (C) 2019 Associação Brasileira de Metalurgia, Materiais e Mineração. Publicado pela ABM. Este é um artigo de acesso aberto distribuído sob os termos da licença Creative Commons CC BY-NC-ND (Attribution-NonCommercial-NoDerivs) - https:// creativecommons.org/licenses/by-nc-nd/4.0/. 
Tabela I. Especificação de composição química dos aços do estudo (\% em peso)

\begin{tabular}{ccccccc}
\hline Aço & $\mathbf{C}$ & $\mathbf{M n}$ & $\mathbf{S i}$ & $\mathbf{C r}+\mathbf{M o}$ & $\mathbf{T i}+\mathbf{N b}$ & $\mathbf{B}$ \\
\hline Convencional & $\leq 0,23$ & $\leq 3,30$ & $\leq 2,00$ & - & $\leq 0,05$ & - \\
Experimental & $\leq 0,15$ & $\leq 3,30$ & $\leq 2,00$ & $\leq 0,45$ & $\leq 0,05$ & $\leq 0,0040$ \\
\hline
\end{tabular}
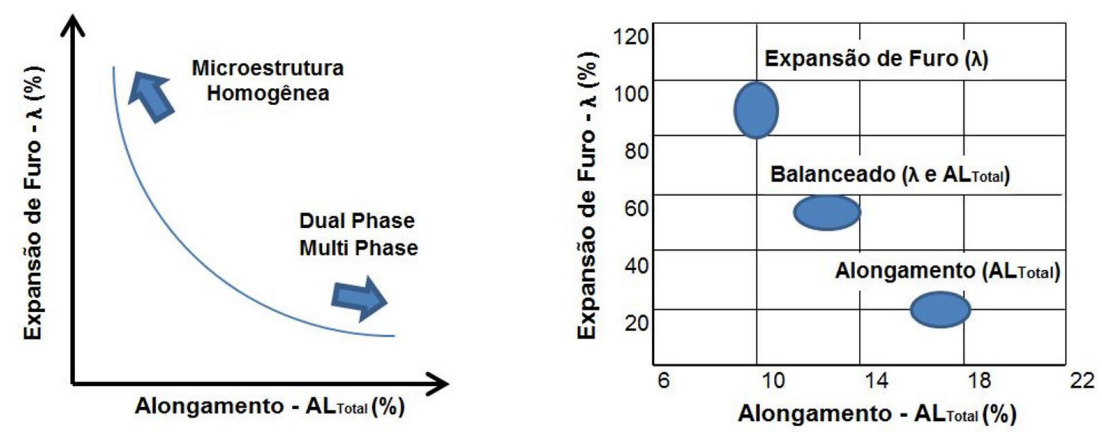

Figura I. Relação entre microestruturas adequadas para expansão de furo e alongamento [I].

Este trabalho mostra o desenvolvimento de diferentes concepções de aço do grau $980 \mathrm{MPa}$ de resistência. Na Figura I é mostrada uma relação entre diferentes microestruturas, alongamento e expansão de furo, conforme estabelecido por Fujita [I]. A partir de um aço bifásico tradicional, foram feitas modificações em composição química, simulados ciclos térmicos de recozimento contínuo e gerados produtos em escala industrial. Foram realizadas caracterizações microestrutural e mecânica para avaliá-los comparativamente.

\section{MATERIAIS E MÉTODOS}

Na primeira etapa do estudo foi produzida uma corrida experimental com modificações na composição química em relação ao aço convencional, produzido pela empresa. Conforme mostrado na Tabela I, o teor de carbono foi reduzido e foram adicionados outros elementos para aumentar a temperabilidade da liga.

Foram produzidas bobinas laminadas a frio (sem recozimento) com I, $20 \mathrm{~mm}$ de espessura, em escala industrial, das quais foram coletadas amostras. Essas foram cortadas nas dimensões $150 \mathrm{~mm} \times 50 \mathrm{~mm}$ e submetidas a quatro ciclos térmicos distintos em escala piloto (Simulador Gleeble 3500), conforme representação esquemática (Figura 2). A taxa de resfriamento foi em torno de $-35^{\circ} \mathrm{C} / \mathrm{s} \mathrm{e}$ a velocidade de $100 \mathrm{~m} / \mathrm{min}$, baseadas no processo industrial.

As alternativas testadas em termos de composição química e ciclo de recozimento nortearam o desenvolvimento de dois novos tipos de aço da classe de $980 \mathrm{MPa}$ de limite de resistência mínimo, além do aço convencional. Em conformidade com a nomenclatura adotada por Fujita [I], estes aços foram assim denominados:

- Convencional: composição química à base de $\mathrm{C}-\mathrm{Mn}-\mathrm{Si}$. Este material apresenta microestrutura constituída tipicamente por ferrita (F) e martensita (M). Suas propriedades mecânicas se caracterizam por

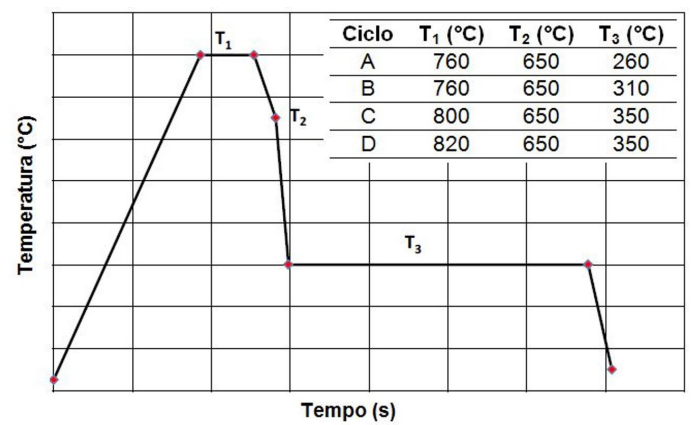

Figura 2. Representação esquemática dos ciclos térmicos simulados na Gleeble.

apresentar baixa relação elástica e alta capacidade de alongamento, porém com valores moderados de expansão de furo;

- Balanceado: a partir da nova composição química e ciclos $A$ e $B$ em escala piloto para buscar uma microestrutura mais balanceada com ferrita $(F)$, martensita $(M)$ e bainita (B) e menor diferença de dureza entre os constituintes. Tende a apresentar uma solução de compromisso entre alongamento $\left(A L_{\text {Total }}\right)$ e expansão de furo $(\lambda)$;

- Expansão de Furo: teste com a composição química experimental e ciclos $C$ e $D$ em escala piloto. Apresenta microestrutura majoritariamente bainítica, a fim de maximizar a capacidade de expansão de furo, porém sacrificando relativamente seu alongamento total.

A partir dos resultados em escala piloto foram realizados testes industriais visando a produção destes novos produtos em escala comercial. Foi realizada uma nova amostragem em produtos gerados no recozimento contínuo, com I, 20 mm de espessura. Para um comparativo entre os novos aços e o convencional, foram realizados testes de expansão de furo e tração a temperatura ambiente, além de caracterização microestrutural. 
Os ensaios de tração foram realizados de acordo com a norma ASTM A370 [3] para corpos de prova de tamanho reduzido (sub-size), com os valores médios sendo obtidos a partir de três corpos de prova individuais para cada amostra tratada na Gleeble. O mesmo esquema foi utilizado para a amostragem em escala industrial.

A caracterização microestrutural foi realizada por microscopia óptica (MO) e microscopia eletrônica de varredura (MEV) em seções à 1/4 da espessura, orientadas paralelamente à direção de laminação. Para determinação da fração volumétrica dos microconstituintes por metalografia quantitativa utilizou-se do reativo nital (2\%) para classificação da microestrutura em ferrita e segundo constituinte.

Os ensaios de expansão de furo foram realizados com base na norma ISO/TS 16630 [4], a partir de três corpos de prova para cada ciclo térmico (dimensões $150 \times 50 \mathrm{~mm}$ ). O valor da razão de expansão de furos $(\lambda)$ de cada ciclo foi calculado como média dos resultados destes três corpos de prova.

\section{RESULTADOS E DISCUSSÃO}

\section{I Avaliação da Nova Composição Química em Escala Piloto}

Foram avaliadas as seguintes propriedades mecânicas: Limite de Escoamento (LE), Limite de Resistência (LR), Alongamento Total ( $A L_{\text {Total }}$ ) e Razão de Expansão de Furo $(\lambda)$, conforme resultados apresentados na Tabela 2.

Os resultados da etapa em escala piloto mostraram uma tendência de queda em todas as propriedades mecânicas avaliadas com a elevação da temperatura de overaging $\left(\mathrm{T}_{3}=260^{\circ} \mathrm{C}\right.$ para $310^{\circ} \mathrm{C}$ ), quando se comparam os resultados dos ciclos $A$ e $B$ (ambos com $\mathrm{T}_{1}=760^{\circ} \mathrm{C} \mathrm{e} \mathrm{T}_{2}=650^{\circ} \mathrm{C}$ ).

$O$ aumento da temperatura de encharque $\left(T_{1}=800^{\circ} \mathrm{C}\right.$ para $820^{\circ} \mathrm{C}$ ), entre os ciclos $\mathrm{Ce} \mathrm{D}$ (ambos com $\mathrm{T}_{2}=650^{\circ} \mathrm{C}$ e $\mathrm{T}_{3}=350^{\circ} \mathrm{C}$ ) elevou a razão de expansão de furo para valores superiores a $60 \%$ e LR $>980 \mathrm{MPa}$. Foi verificada também a tendência de aumento de LE e LR, e redução no $A L_{\text {Total }}$ com o incremento do encharque.
O acréscimo na temperatura de overaging ocorrida entre os ciclos $\mathrm{A}$ e $\mathrm{B}\left(\mathrm{T}_{3}=260^{\circ} \mathrm{C}\right.$ para $\left.310^{\circ} \mathrm{C}\right)$, geralmente favorece a formação de bainita (em detrimento da martensita) ou de martensita revenida, de menor dureza [2,5], o que não pôde ser confirmado nesse estudo. Isto poderia explicar as quedas verificadas em $L E, L R$ e $A L_{\text {Total }}$ A diminuição da capacidade expansão de furo do material, embora relativamente pequena, com o incremento da temperatura de overaging, para o caso específico dos ciclos A e B, precisaria ser investigada mais detalhadamente. Não foi possível fazê-lo no escopo deste estudo.

Os valores mais baixos de LE e LR para os ciclos $A$ e $B$ podem ser explicados pela menor temperatura de encharque $\left(T_{1}=760^{\circ} \mathrm{C}\right)$, que tende a produzir uma microestrutura com fração de ferrita relativamente maior, quando comparada aos ciclos $C\left(T_{1}=800^{\circ} \mathrm{C}\right)$ e $D\left(T_{1}=820^{\circ} \mathrm{C}\right)$. Com a elevação dessa temperatura, a tendência é a diminuição da fração de ferrita, e consequente incremento da quantidade de constituintes de maior dureza [ $\mathrm{I}]$. Isso explica $\mathrm{O}$ aumento dos valores de $L E, L R, \lambda$ e redução do $A L_{\text {Total }}$ conforme mostrado na Tabela 2.

\subsection{Comparativo Entre os Aços em Escala Industrial}

A partir dos resultados em escala piloto, foram feitos testes industriais com pequenas adequações no ciclo térmico em relação à escala piloto para a nova composição química. Foram feitas amostragens dos dois novos aços ("Balanceado" e "Expansão de Furo") além do "Convencional" para um comparativo entre suas características.

Conforme resultados apresentados na Tabela 3, os valores de LE dos aços "Convencional" e "Balanceado" foram similares, porém bem menores que os de "Expansão de Furo". Os resultados de LR, por outro lado, ficaram bem próximos. Em função dessas diferenças, os valores de razão elástica desse último aço apresentaram-se maiores comparativamente. Seu valor de $\mathrm{AL}_{\text {Total }}$ também foi menor.

O melhor desempenho no teste de expansão de furo $(\lambda)$, conforme esperado, foi do aço para "Expansão de Furo", com resultado de $\lambda$ quase cinco vezes maior que o aço "Convencional".

Tabela 2. Resultados de tração (direção transversal) e $\lambda$ entre ciclos testados

\begin{tabular}{|c|c|c|c|c|c|c|c|c|}
\hline \multirow{2}{*}{ Ciclo } & \multicolumn{2}{|c|}{ LE (MPa) } & \multicolumn{2}{|c|}{ LR (MPa) } & \multicolumn{2}{|c|}{$\mathrm{Al}_{\text {Total }}(\%)$} & \multicolumn{2}{|c|}{$\lambda(\%)$} \\
\hline & Média & Desvio & Média & Desvio & Média & Desvio & Média & Desvic \\
\hline A & 566,0 & 17,00 & 961,0 & 14,80 & 15,0 & 0,40 & 27,0 & 0,70 \\
\hline B & 534,0 & 31,10 & 913,5 & 2,10 & 13,0 & $\mathrm{I}, 50$ & 22,0 & $\mathrm{I}, 40$ \\
\hline C & 787,0 & 4,20 & 995,0 & $\mathrm{I}, 40$ & 14,0 & 0,40 & 50,0 & 2,10 \\
\hline D & 957,5 & 31,80 & 1065,0 & 19,10 & 11,0 & 0,40 & 69,0 & 10,90 \\
\hline
\end{tabular}

Tabela 3. Resultados de tração (direção longitudinal) e $\lambda$ dos aços em escala industrial

\begin{tabular}{|c|c|c|c|c|c|c|c|c|}
\hline \multirow{2}{*}{ Aço } & \multicolumn{2}{|c|}{ LE (MPa) } & \multicolumn{2}{|c|}{ LR (MPa) } & \multicolumn{2}{|c|}{$\mathrm{AL}_{\text {Total }}(\%)$} & \multicolumn{2}{|c|}{$\lambda(\%)$} \\
\hline & Média & Desvio & Média & Desvio & Média & Desvio & Média & Desvio \\
\hline Convencional & 639,3 & 1,15 & 1031,7 & 1,53 & 16,2 & 0,40 & 11,3 & 0,58 \\
\hline Balanceado & 655,7 & $\mathrm{I}, \mathrm{I} 5$ & $|00|, 7$ & 2,52 & $15, \mid$ & 0,42 & 25,3 & 0,58 \\
\hline Exp. de Furo & 853,0 & 2,00 & 1017,7 & 3,21 & 10,8 & 0,21 & 53,7 & 5,03 \\
\hline
\end{tabular}

Tecnol. Metal. Mater. Miner., São Paulo, 

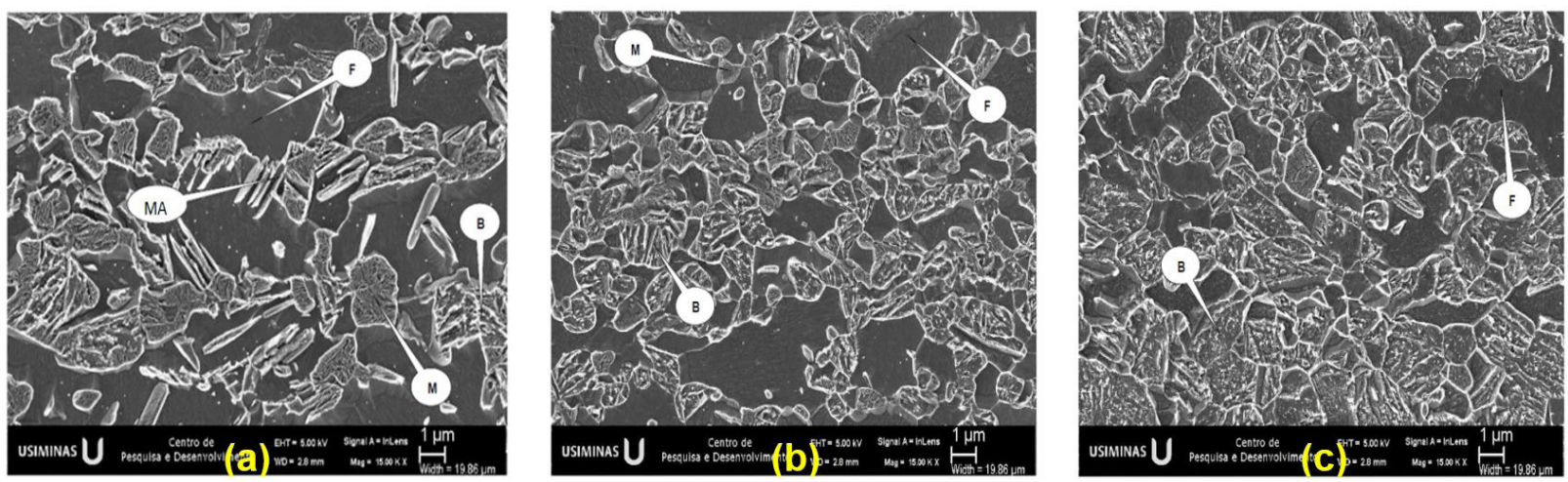

Figura 3. Aspecto típico da microestrutura dos aços estudados, observados via MEV, seção longitudinal ao sentido de laminação, nital $2 \%$. (a) Convencional (b) Balanceado (c) Exp. de Furo. F: ferrita; B: bainita; M: martensita; MA: martensita-austenita.

Esse último aço apresentou piores resultados provavelmente em função da quantidade de carbono mais elevada, formando uma martensita de maior dureza, mais rica nesse elemento e consequentemente com maior diferença de dureza comparada à fase ferrítica. Não foi possível tal medição, mas verifica-se em literatura $[1,6]$ que quanto maior tal gradiente, menor a capacidade de expansão de furo. Isso explica o comportamento do aço "Expansão de Furo", constituído em maior parte por bainita em adição à ferrita, com diferença de dureza menos acentuada entre esses constituintes.

A fração volumétrica das fases presentes nos aços estudados é apresentada na Tabela 4, onde o segundo constituinte é considerado como a soma de bainita (B), martensita (M) e martensita-austenita (MA). Na Figura 3 são apresentados os resultados das análises via MEV.

O aço "Balanceado" apresentou microestrutura constituída por bainita e ferrita, além de algumas partículas de martensita vistas em maiores ampliações (Figura 3b). Não foi possível diferenciar de forma quantitativa a bainita da martensita, sendo referido na Tabela 4 como B+M+MA. Esse aço apresentou em torno de $20 \%$ de ferrita.

O aço para "Expansão de Furo" apresentou microestrutura com maior parte de bainita, sem presença de martensita, nem mesmo nos contornos da bainita, com $15 \%$ de ferrita (Figura 3c). A presença de ferrita nesses aços, mesmo em pequenas quantidades, gera um aumento no $A L_{\text {Total }}$, porém diminui a $\lambda$ e LE. Portanto, não é desejada para aplicações com requisito de expansão de furo. $\mathrm{O}$ aço "Convencional" apresentou microestrutura formada por bainita, ferrita, martensita e martensita-austenita (Figura 3a).

A característica microestrutural mais próxima de um aço bifásico explica os valores de $\mathrm{AL}_{\text {Total }}$ elevados tanto para o aço "Convencional" quanto para o "Balanceado", com a ferrita controlando a deformação do material devido ao número de deslocações livres, gerando maior ductilidade. No caso do aço "Expansão de Furo", suspeita-se que a bainita em maior fração volumétrica na microestrutura controle a deformação e diminua a ductilidade comparativamente. O maior volume de ferrita e a presença de martensita nos dois primeiros aços apresentados proporcionou menor valor de LE. As deslocações livres geradas durante a
Tabela 4. Resultados da quantificação de fases via microscopia óptica (desvio: 2\%)

\begin{tabular}{ccc}
\hline Aço & Ferrita (\%) & B+M+MA (\%) \\
\hline Convencional & 17,2 & 82,8 \\
Balanceado & 25,9 & 74,1 \\
Exp. de Furos & 13,6 & 86,4 \\
\hline
\end{tabular}

transformação martensítica apresentam maior mobilidade na ferrita, reduzindo a carga inicial necessária para iniciar a deformação plástica, justificando esses resultados mais baixos de $L E$ e mais elevados de $A L_{\text {Total }}$ Para o aço "Expansão de Furo", a deformação foi dividida entre bainita e ferrita, com cargas maiores para iniciar o escoamento.

\section{CONCLUSÃO}

$\mathrm{Na}$ etapa de escala piloto, os ciclos com encharque de $760{ }^{\circ} \mathrm{C}$ apresentaram LR abaixo de $980 \mathrm{MPa}$. Além disso, o aumento da temperatura de overaging de 260 para $310^{\circ} \mathrm{C}$ promoveu uma queda adicional do $L E, L R, \mathrm{AL}_{\text {Total }} \mathrm{e} \lambda$, embora este último resultado tenha sido superior a $20 \%$. $\mathrm{O}$ aumento da temperatura de encharque, de $800{ }^{\circ} \mathrm{C}$ para $820^{\circ} \mathrm{C}$, propiciou maiores valores de $\lambda$, acima de $50 \%$, além de ganhos em LE e LR, porém com redução do $\mathrm{AL}_{\text {Total }}$.

Os resultados obtidos na escala industrial foram consistentes com os da escala piloto. $O$ aço experimental "Expansão de Furo" no geral apresentou melhores resultados quanto aos parâmetros de estampabilidade, com bom desempenho ao ser submetido a esforços de estiramento de flange, consequentemente dobramento, mostrando-se apto a ser utilizado em peças com maior diversidade geométrica. O aço "Convencional" apresentou ductilidade mais elevada e menor razão de expansão de furo comparativamente. O aço "Balanceado" apresentou a combinação de boa ductilidade e capacidade de expansão de furo acima de $20 \%$. 


\section{REFERÊNCIAS}

I Fujita N, Nonaka T, Tomokiyo T, Taniguchi H, Goto K. Development of ultra-high strength of $980 \mathrm{MPa}$. SAE International. 2007; 5I-55.

2 Pathak N, Butcher C, Worswick M, Bellhouse E, Gao J. Damage evolution in Complex and Dual Phase steels during edge stretching. Materials. 2017;10:346.

3 American Society for Testing and Materials. ASTM A 370: Test methods and definitions for mechanical testing of steel products. West Conshohocken: ASTM; 2014.

4 International Organization Standardization. ISO/TS 16630: Metallic materials method of hole expanding test. West Conshohocken: ASTM; 2003.

5 Pushkareva I, Allain S, Scott C, Redjaimia A, Moulin A. Relationship between microstructure, mechanical properties and damage mechanisms in high martensite fraction Dual Phase steels. ISIJ International. 20 I5;55:2237-2246.

6 Terrazas OR, Findley KO, Van Tyne CJ. Influence of martensite morphology on sheared-edge formability of dualphase steels. ISIJ International. 2017;57:937-944.

Recebido em: 4 Dez. 2018

Aceito em: 9 Out. 2019 